\title{
Redox mediators modify end product distribution in biomass fermentations by mixed ruminal microbes in vitro
}

\author{
Michael A Nerdahl ${ }^{1}$ and Paul J Weimer ${ }^{1,2,3^{*}}$
}

\begin{abstract}
The fermentation system of mixed ruminal bacteria is capable of generating large amounts of short-chain volatile fatty acids (VFA) via the carboxylate platform in vitro. These VFAs are subject to elongation to larger, more energydense products through reverse $\beta$-oxidation, and the resulting products are useful as precursors for liquid fuels production. This study examined the effect of several redox mediators (neutral red, methyl viologen, safranin $\mathrm{O}$, tannic acid) as alternative electron carriers for mixed ruminal bacteria during the fermentation of biomass (ground switchgrass not subjected to other pretreatments) and their potential to enhance elongation of end-products to medium-chain VFAs with no additional run-time. Neutral red (1 mM) in particular facilitated chain elongation, increasing average VFA chain length from 2.42 to 2.97 carbon atoms per molecule, while simultaneously inhibiting methane accumulation by over half yet maintaining total $\mathrm{C}$ in end products. The ability of redox dyes to act as alternative electron carriers suggests that ruminal fermentation is inherently manipulable toward retaining a higher fraction of substrate energy in the form of VFA.
\end{abstract}

Keywords: Electron mediator, Methane, Redox dye, Rumen, Volatile fatty acids

\section{Introduction}

One of the greatest needs in developing sustainable alternative energy systems is an economical means of producing energy-dense, infrastructure-compatible liquid fuels (Granda et al. 2007). Mixed cultures of microorganisms can degrade biomass to mixtures of volatile fatty acids (the carboxylate platform; Agler et al. 2011) that can then be converted by further chemistry to useful bioproducts, including liquid fuels (Holtzapple and Granda 2009; Lange et al. 2010; Levy et al. 1981). The carboxylate platform has been highlighted for its ability to be operated non-aseptically, generate high yields, and utilize a wide range of feedstocks, owing to the metabolic diversity of the undefined microbial community (Agler et al. 2011). Within the carboxylate platform, efforts have been made to improve its economics by increasing the value of

\footnotetext{
*Correspondence: Paul.Weimer@ars.usda.gov

3 Present Address: Department of Plant Pathology and Microbiology, Texas A\&M University, 435 Nagle Street, College Station, TX 77843-2132, USA

Full list of author information is available at the end of the article
}

products while still working within reasonable operating costs and run-times (Agler et al. 2012).

Ruminal fermentation is the means by which ruminant animals convert plant biomass to volatile fatty acids (VFA) that serve as energy source for the host animal. When conducted outside the animal (i.e., in bioreactors), the ruminal fermentation can be considered as a type of consolidated bioprocessing system that has the potential to improve upon the existing carboxylate platform for fuels and chemical production. In a manner similar to other undefined mixed cultures, such as sewage sludge or aquatic sediments, the mixed ruminal bacteria are capable of digesting a wide range of substrates (Weimer 2011). Of particular note for the ruminal bacteria is their capability to produce large amounts of short-chain volatile fatty acids (VFA) from cellulosic substrates in run times as short as 1-3 days. Likewise, the accumulation of methane in these systems is considerably lower than in most anaerobic digestion processes due to a lack of aceticlastic methanogens and protonreducing acetogens, which require more time for

\section{Springer}


growth than the short 1-3 day ruminal retention times allow, limiting their effect (Weimer et al. 2009). The ability of ruminal bacteria to produce substantial VFA yields has been well-documented and efforts have been made to elongate these short-chain VFAs to mediumchain VFAs, which are more energy-dense and more easily extractable (Singhania et al. 2013). The propensity of the ruminal bacteria towards VFA generation at considerable yield in such short run times deems it worthy of continued study with respect to chain elongation, and what low-cost methods can be used to manipulate the ruminal end-products to more valuable alternatives without altering the initial microbial composition, i.e. without addition of other bacteria. End product manipulation may also be beneficial within the rumen itself, as part of strategy for decreasing methane emissions and retaining feed energy in VFA in vivo, as this is a recognized as a fundamental goal of economically and environmentally sustainable animal agriculture (Hristov et al. 2013).

One important means of contributing to these goals is to better characterize the inherent manipulability of the ruminal fermentation under in vitro ("extraruminal") conditions. The use of redox mediators has the potential to improve our understanding of how readily fermentation end product ratios may be altered in this system. This study examines the ability of several redox mediators-neutral red, methyl viologen, safranin O, and tannic acid-to decrease methanogenesis and shift ruminal fermentation end-products in vitro in short (72 h) runtimes, as a means of demonstrating the inherent manipulability of the ruminal fermentation system.

\section{Materials and Methods}

\section{Feedstocks and chemicals}

Switchgrass (Panicum virgatum L.) air-dried whole herbage (late maturity, low quality, harvested after overwintering in February 2013) was generously provided by K. J. Shinners, University of Wisconsin-Madison. The material was ground through Wiley mill $(1 \mathrm{~mm})$ but otherwise was not subjected to additional pretreatment, and was stored at room temperature in the dark. Analysis (in triplicate) using the detergent fiber method of Goering and Van Soest (1970; without $\alpha$-amylase treatment) revealed a composition [g $(\mathrm{kg} \mathrm{DM})^{-1}$ ] of: neutral detergent fiber, $878 \pm 9$; acid detergent fiber, $537 \pm 1$; and acid-detergent lignin, $86 \pm 5$. The $\mathrm{N}$ content, determined using a Leco TruMac (St. Joseph, MI, USA) combustion analyzer, was $5.2 \pm 0.1 \mathrm{~g}(\mathrm{~kg} \mathrm{DM})^{-1}$. DM content of the ground switchgrass was $924 \mathrm{~g}(\mathrm{~kg} \mathrm{DM})^{-1}$.

The following redox mediators were used in their oxidized form: methyl viologen (MV, Acros, 98\% dye content); neutral red (NR, Sigma, 95\% dye content); safranin
O (Aldrich, 96\% dye content), resazurin (Sigma, 85\% dye content); tannic acid (TA, Aldrich).

\section{Ruminal inocula}

Inocula were obtained from two lactating Holstein cows each fitted with a ruminal cannula (Bar-Diamond, Parma, ID, USA). The cows were fed a total mixed ration that contained corn silage, alfalfa haylage, ground corn grain, soybean meal and a vitamin and mineral mix. Ruminal contents (solids and liquids) from each cow were collected manually, then processed and the separate diluted ruminal fluid from each cow combined as described previously (Mouriño et al. 2001).

\section{Fermentations}

All fermentations were conducted in triplicate within treatment, under a $\mathrm{CO}_{2}$ gas phase in volume-calibrated glass serum vials (Wheaton) of $\sim 60 \mathrm{~mL}$ volume fitted with butyl rubber closures and aluminum crimp seals. Experiments were conducted using freshly collected and diluted ruminal inocula. Vials contained Goering-Van Soest medium (1970) reduced with cysteine and $\mathrm{Na}_{2} \mathrm{~S}$, along with the switchgrass [19 $\mathrm{mg}$ DM (mL liquid volume $)^{-1}$. Total liquid volume in the vials was typically $10 \mathrm{~mL}$, except for the NR concentration experiment $(22 \mathrm{~mL})$. Unless otherwise indicated, resazurin was added at low concentrations $(0.008 \mathrm{mM})$ as a redox indicator to confirm (via decolorization upon reduction) establishment of reducing conditions in the culture media. Each redox mediator was dissolved in $\mathrm{N}_{2}$-gassed, deionized water to achieve a $\sim 20 \mathrm{mM}$ stock solution and added to fermentation vials to achieve the indicated concentration in the medium. Each experiment included control vials that lacked redox mediators, as well as blank vials that contained media and inoculum but lacked switchgrass or redox mediators. All experimental setup and incubations were conducted under non-aseptic conditions, with no sterilization of vessels, apparatus, biomass feedstocks, or culture media. Incubations were performed $39^{\circ} \mathrm{C}$ in a static upright position for $72 \mathrm{~h}$.

\section{Analysis of residual substrate and fermentation products}

Analysis of gas phase $\mathrm{H}_{2}$ and methane was conducted by removal of fixed volumes $(0.20-0.40 \mathrm{~mL})$ of headspace using a pressure-lock syringe, and direct injection into a Shimadzu 8A gas chromatograph fitted with a $1.88 \mathrm{~m} \times 3.18 \mathrm{~mm}$ (i.d.) stainless steel column packed with Carbosieve S-II (Sigma-Aldrich, St. Louis, MO, USA). The following chromatographic conditions were used: carrier gas, He; injector $\mathrm{T}, 120^{\circ} \mathrm{C}$; oven $\mathrm{T}, 70^{\circ} \mathrm{C}$; detector $\mathrm{T}, 120^{\circ} \mathrm{C}$; detector type, thermal conductivity; detector current, $120 \mathrm{~mA}$. External standard curves were used for quantification of $\mathrm{H}_{2}$ and $\mathrm{CH}_{4}$. 
Culture $\mathrm{pH}$ was measured immediately after removal of the rubber stopper (to minimize alkalinization of medium that results from $\mathrm{CO}_{2}$ outgassing), using a Mettler-Toledo FiveEasy Plus $\mathrm{pH}$ meter calibrated with $\mathrm{pH} 4.01$ and 7.00 buffers. Volatile fatty acids, nonvolatile acids (lactate, succinate) and ethanol in the culture liquid phase were determined by HPLC, as described previously (Weimer et al. 1991). For all gaseous and nongaseous products, net product formation was calculated after subtraction of products contained in substrate-free blank vials inoculated and incubated with the blank vials. Total enthalpy of combustion of products was calculated from enthalpies of combustion of individual end products (Weast 1969) at their measured net molar concentrations.

Total substrate consumption was calculated as initial dry weight of substrate minus neutral detergent fiber (NDF) residue (equivalent to plant cell wall residue). Residual NDF was determined gravimetrically by a modified Goering and Van Soest method (Weimer et al. 1990).

\section{Statistical analysis}

Statistical tests were performed using PROC MIXED in SAS, v.9.4 (SAS, Cary, NC, USA), using the model $\mathrm{Y}_{\mathrm{i}}=\mu+\mathrm{S}_{\mathrm{i}}+\varepsilon_{\mathrm{i}}$, where $\mathrm{Y}_{\mathrm{i}}=$ dependent variable; $\mu=$ overall mean; $S_{i}=$ effect of redox dye or its concentration; and $\varepsilon_{\mathrm{i}}=$ residual error. For analysis of data from the experiment conducted at different resazurin concentrations, the model $Y_{i}=\mu+S_{i}+R_{i}+S_{i j}+\varepsilon_{I}$ was used, where $R_{i}=$ resazurin concentration. For fermentations conducted at different neutral red concentrations, PROC REG was used for linear and quadratic regression analysis. Data are reported as least-square means. Means separation tests were conducted using the Tukey procedure. Significance was declared at $P<0.05$, and trends identified at $0.05<P<0.10$.

\section{Results}

Fermentations of switchgrass by the mixed ruminal inoculum yielded varying amounts of methane and $\mathrm{C}_{2}-\mathrm{C}_{6}$ VFA. Product concentrations were notably altered by the addition of all three redox dyes $\mathrm{MV}$, NR, or safranin $\mathrm{O}$ (Table 1). MV addition resulted in slightly increased concentrations of caproate $\left(\mathrm{C}_{6}\right)$ and a ninefold increase in the sum of the molar amounts of $\mathrm{C}_{4}$ and $\mathrm{C}_{5}$ branched-chain VFA (isobutyrate, isovalerate and 2-methylbutyrate), but decreased concentrations of methane and $\mathrm{C}_{2}-\mathrm{C}_{4}$ VFA (acetate, propionate, and butyrate), and also decreased total carbon in VFA. Safranin O largely inhibited total VFA carbon and numerically decreased caproate and valerate to near their detection limits. Butyrate production did increase, however, which led to an increase in average carbon chain length to 2.61, compared to 2.42 in the mediator-free control. NR inhibited methane production (by $56 \%$ ) and significantly increased valerate, caproate, and $\mathrm{C}_{4}-\mathrm{C}_{5}$ branched chain VFA, and numerically increased total VFA carbon production.

Table 1 End products from in vitro switchgrass fermentations by mixed ruminal microorganisms in the presence or absence of redox dyes

\begin{tabular}{|c|c|c|c|c|c|c|}
\hline \multirow[t]{2}{*}{ Product } & \multicolumn{4}{|l|}{ Net umol product ${ }^{a}$} & \multirow[t]{2}{*}{ SED $^{b}$} & \multirow[t]{2}{*}{ Model $P>\mathrm{F}$} \\
\hline & Methyl viologen (0.5 mM) & Neutral red (1.0 mM) & Safranin $\mathrm{O}(1.0 \mathrm{mM})$ & Control (no dye) & & \\
\hline Methane & $122.1 \mathrm{~A}$ & $62.1 \mathrm{~B}$ & $38.5 \mathrm{~B}$ & $139.2 \mathrm{~A}$ & 9.9 & $<0.0001$ \\
\hline Acetate & $269.8 \mathrm{~A}$ & $182.0 \mathrm{~B}$ & $142.9 B$ & $305.6 \mathrm{~A}$ & 13.7 & $<0.0001$ \\
\hline Propionate & $60.4 C$ & $119.7 \mathrm{~A}$ & $48.0 \mathrm{C}$ & $91.0 \mathrm{~B}$ & 5.0 & $<0.0001$ \\
\hline Butyrate & $24.0 \mathrm{~B}$ & $40.2 \mathrm{AB}$ & $48.8 \mathrm{~A}$ & $38.8 \mathrm{AB}$ & 5.9 & 0.018 \\
\hline Isobutyrate & $9.7 \mathrm{~A}$ & $4.3 \mathrm{~B}$ & $0.8 \mathrm{C}$ & $1.8 \mathrm{C}$ & 0.7 & $<0.0001$ \\
\hline Valerate & $6.8 \mathrm{~B}$ & $35.9 \mathrm{~A}$ & $1.5 \mathrm{C}$ & $5.3 \mathrm{BC}$ & 1.4 & $<0.0001$ \\
\hline Isoval $+2 \mathrm{MB}^{\mathrm{C}}$ & $19.1 \mathrm{~A}$ & $14.4 \mathrm{~B}$ & $0.1 \mathrm{C}$ & $1.4 \mathrm{C}$ & 1.0 & $<0.0001$ \\
\hline Caproate & $6.7 \mathrm{~A}$ & $8.1 \mathrm{~A}$ & $0.3 \mathrm{~B}$ & $2.1 \mathrm{~B}$ & 1.6 & 0.003 \\
\hline Total VFA & $399.1 \mathrm{~A}$ & $404.1 \mathrm{~A}$ & $242.3 B$ & $441.5 \mathrm{~A}$ & 15.4 & $<0.0001$ \\
\hline Total VFA-C & 1025.6 B & $1201.3 \mathrm{~A}$ & $629.6 C$ & $1,092.0 \mathrm{AB}$ & 40.5 & $<0.0001$ \\
\hline$A C L^{d}$ & $2.58 \mathrm{~B}$ & $2.97 \mathrm{~A}$ & $2.61 B$ & $2.42 \mathrm{C}$ & 0.04 & $<0.0001$ \\
\hline Enthalpy of combustion, kJ & $0.602 \mathrm{~B}$ & $0.667 \mathrm{~A}$ & $0.343 \mathrm{C}$ & $0.633 \mathrm{AB}$ & 0.009 & $<0.0001$ \\
\hline
\end{tabular}

Vials contained $100 \mathrm{mg}$ switchgrass and $3.0 \mathrm{~mL}$ of diluted mixed ruminal inoculum in a total liquid volume of $10 \mathrm{~mL}$.

a Values are least-square means from triplicate cultures after $72 \mathrm{~h}$ incubation, after correction for inoculated blank vials lacking switchgrass. Values within row having different letters $(A, B, C)$ differ $(P<0.05)$.

b Pooled standard error of the difference.

c Isovalerate plus 2-methylbutyrate (chromatographically co-eluting isomers).

d Average chain length of VFA. 
Comparison of the data on a per substrate added basis revealed that only NR numerically increased total end product $\mathrm{C}$ yield while enabling a shift in fermentation to yield longer-chain products (Fig. 1).

Owing to the significant improvement in $\mathrm{C}_{5}$ and $\mathrm{C}_{6}$ VFA production resulting from NR addition, the effect of NR concentration on the fermentation was examined (Fig. 2). Addition of NR in increasing concentrations up to $0.6 \mathrm{mM}$ resulted in linear increases in propionate $(P<0.001)$, butyrate $(P=0.099)$, valerate $(P=0.002)$, caproate $(P<0.001)$ and average VFA chain length

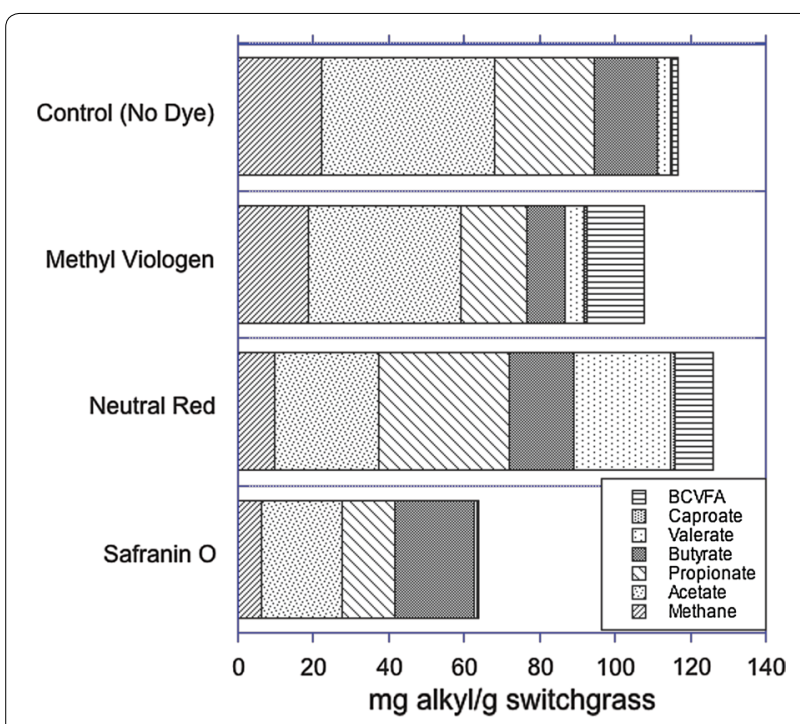

Fig. 1 Effect of the redox dyes methyl viologen $(0.5 \mathrm{mM})$, neutral red (1 $\mathrm{mM})$ and safranin $\mathrm{O}(1 \mathrm{mM})$ on fermentation end product distribution by mixed ruminal microbes in vitro. Data are calculated based on the mass of alkyl groups (methyl plus methylene groups) in the indicated products, per mg of added switchgrass substrate.
(ACL; $\mathrm{P}<0.0001)$. Caproate concentrations increased linearly $(P<0.001)$ from an undetectable concentration $(<0.05 \mathrm{mM})$ in the absence of NR to $2.2 \mathrm{mM}$ at the highest NR concentration, and valerate levels increased by over fourfold to $8.8 \mathrm{mM}$. These increases were accompanied by linear decreases $(P<0.0001)$ in both methane and acetate. At $0.6 \mathrm{mM} \mathrm{NR}$, the highest concentration tested, methane production decreased by $52 \%$ relative to the mediator-free control. Total VFA carbon did not significantly differ among the range of NR concentrations tested (range 434-459 mM, SED $=24.4 \mathrm{mM}, P=0.59$ ).

Another possible redox mediator, tannic acid, was tested to determine whether it could also alter fermentation product distribution (Table 2). The addition of tannic acid in concentrations of 0.1 and $0.3 \mathrm{~g} \mathrm{~L}^{-1}$ produced minimal effects on average chain length (ACL) and total VFA yield. The highest level of tannic acid tested, $1.0 \mathrm{~g} \mathrm{~L}^{-1}$, resulted in a decrease in the amount of switchgrass digested; a slight suppression methane and propionate yields; and a slight decrease in overall ACL of the VFA.

In order to test whether the redox indicator resazurin contributed to the shift in fermentation products in the above experiments (i.e., by acting as a primary or secondary electron carrier), fermentations were conducted in which resazurin was added at concentrations of $0,0.008,0.03,0.10,0.25$, and $0.45 \mathrm{mM}$. No differences were observed among these treatments with respect to substrate consumption or product formation (Table 3). In addition, switchgrass fermentations were conducted with $0.5 \mathrm{mM} \mathrm{NR}$ in the presence or absence of $0.008 \mathrm{mM}$ resazurin (the concentration used in other experiments). As in previous experiments, the addition of NR resulted in significantly lower production of methane as well as acetate with significantly
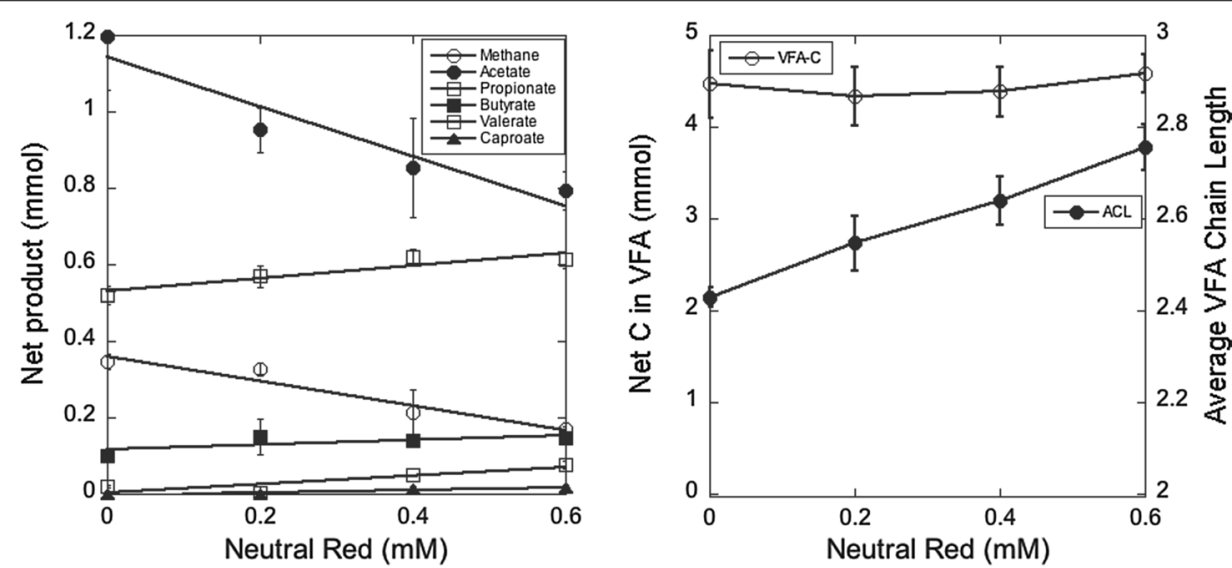

Fig. 2 Effect of neutral red concentration of fermentation end products by mixed ruminal microbes in vitro. Results are mean values from triplicate cultures. Error bars indicate standard errors of the mean. 
Table 2 Effect of tannic acid (TA) on in vitro switchgrass (SWG) fermentations by mixed ruminal microorganisms

\begin{tabular}{|c|c|c|c|c|c|c|}
\hline \multirow[t]{2}{*}{ Variable } & \multicolumn{4}{|c|}{ Least-square mean values ${ }^{\mathrm{a}}$} & \multirow[t]{2}{*}{ SED $^{b}$} & \multirow[t]{2}{*}{ Model $P>F$} \\
\hline & Control (no TA) & $0.1 \mathrm{~g} \mathrm{TA} \mathrm{L}^{-1}$ & $0.3 \mathrm{~g} \mathrm{TA} \mathrm{L}^{-1}$ & $1.0 \mathrm{~g} \mathrm{TA} \mathrm{L}^{-1}$ & & \\
\hline $\begin{array}{l}\text { SWG digested (mg DM) } \\
\text { mmol product (g SWG consumed) })^{-1}\end{array}$ & $79.3 \mathrm{~A}$ & $79.8 \mathrm{~A}$ & $76.9 \mathrm{~A}$ & $70.0 \mathrm{~B}$ & 2.2 & 0.007 \\
\hline Methane & $1.29 \mathrm{~A}$ & $1.40 \mathrm{~A}$ & $1.19 A B$ & $1.02 \mathrm{~B}$ & 0.079 & 0.015 \\
\hline Acetate & 5.14 & 5.42 & 5.17 & 5.31 & 0.906 & 0.906 \\
\hline Propionate & $2.10 \mathrm{~A}$ & $2.22 \mathrm{~A}$ & $1.95 \mathrm{AB}$ & $1.58 \mathrm{~B}$ & 0.154 & 0.015 \\
\hline Butyrate & 0.342 & 0.420 & 0.345 & 0.334 & 0.052 & 0.370 \\
\hline Valerate & 0.008 & 0.011 & 0.032 & 0 & 0.015 & 0.246 \\
\hline Caproate & 0.013 & 0.018 & 0.014 & 0.014 & 0.003 & 0.197 \\
\hline BCVFA $^{\mathrm{C}}$ & 0.022 & 0.050 & 0.014 & 0.002 & 0.017 & 0.104 \\
\hline Total VFA & 7.62 & 8.13 & 7.52 & 7.13 & 0.68 & 0.568 \\
\hline Total VFA-C & 18.17 & 19.59 & 17.89 & 16.78 & 1.317 & 0.430 \\
\hline Total alkyl in SCFA ${ }^{d}$ & 10.54 & 11.40 & 10.33 & 9.12 & 1.057 & 0.267 \\
\hline $\mathrm{ACL}^{\mathrm{e}}$ & $2.38 \mathrm{~A}$ & $2.40 \mathrm{~A}$ & $2.37 \mathrm{~A}$ & $2.27 \mathrm{~B}$ & 0.024 & 0.024 \\
\hline Final $\mathrm{pH}$ & 6.41 & 6.41 & 6.39 & 6.42 & 0.051 & 0.940 \\
\hline Enthalpy of combustion, kJ (g SWG digested) $)^{-1}$ & 9.74 & 10.51 & 9.52 & 8.77 & 0.827 & 0.287 \\
\hline
\end{tabular}

Vials contained $190 \mathrm{mg}$ switchgrass $\mathrm{DM}$ and $2.0 \mathrm{~mL}$ of diluted mixed ruminal inoculum in a total liquid volume of $10 \mathrm{~mL}$.

${ }^{a}$ Values are from triplicate cultures after $72 \mathrm{~h}$ incubation, after correction for inoculated blank vials lacking SWG. Values within row having different letters (A, B) differ $(P<0.05)$.

b Pooled standard error of the difference.

c Branch-chain $C_{4}-C_{5}$ VFA (sum of isobutyrate, 2-methylbutyrate, and isovalerate).

d Sum of methyl and methylene groups in VFA.

e Average chain length of VFA.

higher production of valerate (although, unexpectedly, no caproate) and increased average VFA chain length. However, the addition of resazurin $(0.008 \mathrm{mM})$ with NR produced no additional increases or decreases in end product concentrations. Thus it does not appear that resazurin can serve as an electron carrier in these fermentations.

In the above fermentations inhibition of methanogenesis by NR was accompanied by accumulation of modest amounts of both $\mathrm{H}_{2}$ and formate. Fermentations containing either 0 or $0.008 \mathrm{mM}$ resazurin with NR (Table 2) averaged $34.9 \mu \mathrm{mol} \mathrm{H}$ atoms in measured fermentation products ( $\mathrm{mg}$ switchgrass digested $)^{-1}$, numerically less than the $40.5 \mu \mathrm{mol} \mathrm{H}$ atoms $(\mathrm{mg}$ switchgrass digested $)^{-1}$ in parallel fermentations lacking NR, but this difference was not significant. However, total $\mathrm{H}$ atoms in measured fermentation products (mg switchgrass digested $)^{-1}$ tended $(P=0.089)$ to be lower in the presence versus absence of NR without resazurin, and was nearly so $(P=0.115)$ with $0.008 \mathrm{mM}$ resazurin, suggesting that there may be additional fermentation products not accounted for in the NRsupplemented cultures. As expected, all cultures had similar enthalpies of combustion on a per mg switchgrass digested basis.

\section{Discussion}

Shifting metabolic products of plant matter degradation to decrease methanogenesis and increase VFA is desirable within the rumen itself (as it should increase energetic efficiency and decrease greenhouse gas emissions) and in extraruminal bioreactors (as it should foster chain elongation to higher-energy, medium chain-length carboxylates). The inherent manipulability of the ruminal fermentation has largely been explored by altering substrate (i.e., diet composition) or by adding specific metabolic inhibitors (e.g., of methanogenesis), but the limits to which the fermentation can be altered, and the mechanisms underlying these alterations, have not been firmly established (Ungerfeld 2015). In this study we used artificial electron acceptors (redox mediators) to examine fermentation end product distribution on a single plant biomass substrate (ground switchgrass not subjected to chemical pretreatment).

The capability of redox dyes to shift anaerobic fermentation towards formation of longer end-products was first examined in non-ruminal systems by Hongo (1958). By diverting reducing equivalents that are normally released as $\mathrm{H}_{2}$ towards formation of $\mathrm{NAD}(\mathrm{P}) \mathrm{H}$, redox dyes can inhibit methanogenesis by decreasing the supply of $\mathrm{H}_{2}$, and provide $\mathrm{NAD}(\mathrm{P}) \mathrm{H}$ for use as reducing power 
Table 3 Effect of resazurin (Res) and Neutral Red (NR) on fermentation of switchgrass (SWG) by mixed ruminal microflora in vitro

\begin{tabular}{|c|c|c|c|c|c|c|c|c|c|c|c|}
\hline \multirow[t]{2}{*}{ Variable } & \multicolumn{6}{|c|}{ Resazurin (Res, in mM) without Neutral Red (NR) } & \multicolumn{2}{|c|}{$0.5 \mathrm{mM} \mathrm{NR}$} & \multirow[t]{2}{*}{ SED $^{a}$} & \multirow{2}{*}{$\begin{array}{l}P>F, \\
\operatorname{Res}^{b}\end{array}$} & \multirow{2}{*}{$\begin{array}{l}P>F, \\
N R^{c}\end{array}$} \\
\hline & No Res & $\operatorname{Res}(0.008)$ & $\operatorname{Res}(0.03)$ & $\operatorname{Res}(0.10)$ & $\operatorname{Res}(0.25)$ & $\operatorname{Res}(0.45)$ & No Res & $\operatorname{Res}(0.008)$ & & & \\
\hline SWG digested(mg) & $74.9 \mathrm{~A}$ & $75.2 \mathrm{~A}$ & $73.3 \mathrm{AB}$ & $72.2 \mathrm{AB}$ & $73.3 A B$ & $70.9 \mathrm{AB}$ & $66.7 \mathrm{ABC}$ & $64.3 \mathrm{BC}$ & 2.39 & 0.597 & 0.967 \\
\hline \multicolumn{12}{|l|}{ Net $\mu \mathrm{mol}$} \\
\hline $\mathrm{H}_{2}$ & $0.13 B$ & $0.14 \mathrm{~B}$ & $0.10 B$ & $0.25 B$ & $0.27 \mathrm{~B}$ & $0.09 \mathrm{~B}$ & $2.23 \mathrm{~A}$ & $2.42 \mathrm{~B}$ & 0.29 & 0.154 & 0.999 \\
\hline Methane & $110.0 \mathrm{~A}$ & $109.6 \mathrm{~A}$ & $108.4 \mathrm{~A}$ & $107.3 \mathrm{~A}$ & $107.7 \mathrm{~A}$ & $106.1 \mathrm{~A}$ & $37.6 \mathrm{~B}$ & $35.2 \mathrm{~B}$ & 3.72 & 0.932 & 0.997 \\
\hline Formate & $O B$ & $1.3 \mathrm{~B}$ & $O B$ & $O B$ & $O B$ & $O B$ & $23.7 \mathrm{~A}$ & $18.1 \mathrm{~A}$ & 4.0 & 0.785 & 0.846 \\
\hline Acetate & $359.1 \mathrm{~A}$ & $339.0 \mathrm{~A}$ & $338.2 \mathrm{~A}$ & $336.7 \mathrm{~A}$ & $337.4 \mathrm{~A}$ & $300.0 \mathrm{~A}$ & $222.7 \mathrm{~B}$ & $208.5 B$ & 18.3 & 0.176 & 0.990 \\
\hline Propionate & 140.1 & 148.2 & 137.5 & 143.8 & 144.7 & 138.4 & 160.5 & 153.7 & 7.44 & 0.714 & 0.976 \\
\hline Butyrate & 30.4 & 26.2 & 27.7 & 25.9 & 26.9 & 25.7 & 30.4 & 27.9 & 3.50 & 0.573 & 0.995 \\
\hline Isobutyrate & $1.3 A B$ & $2.1 \mathrm{~A}$ & $1.7 \mathrm{~A}$ & $0.9 \mathrm{AB}$ & $1.5 \mathrm{AB}$ & $1.0 \mathrm{AB}$ & 0 & 0 & 1.43 & 0.314 & 1.000 \\
\hline Valerate & $4.0 \mathrm{AB}$ & $2.0 \mathrm{~B}$ & $2.5 \mathrm{~B}$ & $2.2 \mathrm{~B}$ & $2.2 \mathrm{~B}$ & $2.2 \mathrm{~B}$ & $5.6 \mathrm{~A}$ & $5.5 \mathrm{~A}$ & 0.78 & 0.227 & 1.000 \\
\hline Isovalerate $+2 \mathrm{MB}$ & 4.7 & 2.6 & 4.4 & 2.2 & 3.3 & 2.4 & 0 & 0 & 1.4 & 0.585 & 1.000 \\
\hline Caproate & 0.31 & 0.38 & 0 & 0 & 0 & 0 & 0 & 0 & 0.14 & 0.113 & 1.000 \\
\hline Total $C_{2}-C_{6}$ VFA & $534.1 \mathrm{~A}$ & $520.5 \mathrm{~A}$ & $512.1 \mathrm{~A}$ & $511.6 \mathrm{~A}$ & $516.0 \mathrm{~A}$ & $469.9 A B$ & $416.7 \mathrm{~B}$ & $391.3 \mathrm{~B}$ & 25.6 & 0.277 & 0.953 \\
\hline Total VFA alkyld & $752.0 \mathrm{~A}$ & $741.0 \mathrm{~A}$ & $729.8 \mathrm{~A}$ & $722.1 \mathrm{~A}$ & $733.7 \mathrm{~A}$ & $675.6 \mathrm{AB}$ & $647.3 \mathrm{~B}$ & $604.5 \mathrm{~B}$ & 33.0 & 0.313 & 0.867 \\
\hline Total alkyle & $861.8 A B$ & $850.6 A B$ & $838.2 A B$ & $829.4 A B$ & $841.5 \mathrm{AB}$ & $781.7 A B$ & $684.9 \mathrm{BC}$ & $639.7 C$ & 34.1 & 0.294 & 0.854 \\
\hline$A C L^{f}$ & $2.41 \mathrm{~B}$ & $2.42 B$ & $2.43 B$ & $2.41 \mathrm{~A}$ & $2.42 \mathrm{~A}$ & $2.44 \mathrm{~B}$ & $2.55 \mathrm{~A}$ & $2.55 \mathrm{~A}$ & 0.024 & 0.454 & 0.997 \\
\hline$\mu \mathrm{mol} \mathrm{H}(\mathrm{mg} \mathrm{SWG})^{-1}$ & 41.31 & 39.44 & 39.94 & 40.14 & 39.97 & 38.30 & 34.48 & 35.34 & 1.88 & 0.806 & 0.965 \\
\hline $\begin{array}{c}\text { Combustion, kJ (g SWG } \\
\text { digested) })^{-1}\end{array}$ & 9.94 & 9.51 & 9.65 & 9.67 & 9.65 & 9.26 & 8.65 & 8.46 & 0.83 & 0.832 & 0.608 \\
\hline
\end{tabular}

Values are least-square means from triplicate cultures that contained $190 \mathrm{mg}$ switchgrass (DM basis), $2.0 \mathrm{~mL}$ diluted ruminal inoculum and $10 \mathrm{~mL}$ total liquid volume. End product amounts from $72 \mathrm{~h}$ fermentations have been corrected for inoculated blank vials that lacked SWG.

a Pooled standard error of the difference.

b Comparison of least-square means across all treatments not containing NR (0-0.45 mM resazurin).

c Comparison of least-square means between NR and NR $+0.008 \mathrm{mM}$ resazurin.

d Sum of methyl plus methylene groups in $\mathrm{C}_{2}-\mathrm{C}_{6}$ VFA.

e Includes methane.

${ }^{f}$ Average chain length of VFA (excluding formate).

$A B C$ different letters within row indicate differences in least-square means $(P<0.05)$.

to synthesize longer chain molecules. Whether a redox mediator may divert electron flow depends on its capability to compete with a natural electron carrier in vivo. MV has a similar redox potential to ferredoxin and thus may replace ferredoxin in hydrogenase-catalyzed reactions (Peguin et al. 1994). That MV may replace ferredoxin allows it to act as a substitute for the direct reduction of $\mathrm{NAD}^{+}$. Accumulation of NADH inhibits further NAD ${ }^{+}$ reduction by either MV or ferredoxin (Rao and Mutharasan 1987). This is the mechanism for production of longer chain products with redox dyes: because a second electron carrier is present, the natural electron carrier will accumulate unless the reaction is coupled to the further synthesis of longer chain molecules that decreases the amount of NADH present in the cell.

Of the redox mediators tested, NR was most effective at decreasing methane production and facilitating VFA chain length extension. The reduction potential of NR (Table 4$)$ is very close to that of NADH $(-0.32 \mathrm{~V})$. Because
Table 4 Reduction potentials of redox mediators

\begin{tabular}{lll}
\hline Redox mediator & $\mathbf{E}^{\circ}(\mathbf{V})$ & References \\
\hline Methyl viologen & -0.446 & Michaelis and Hill (1933) \\
Neutral red & -0.325 & Park et al. (1999) \\
Safranin O & -0.279 & Stieliler et al. (1933) \\
Resazurin & +0.042 & Hungate (1969) \\
Tannins & +0.571 to $+0.996^{\text {a }}$ & Hagerman et al. (1998) \\
\hline
\end{tabular}

a Varies with specific compound; range is at experimental $\mathrm{pH}$ of 6.24 , similar to $\mathrm{pH}$ values of fermentation experiments reported here.

of its similar redox potential, neutral red may act as an electron carrier and perform in enzymatic reactions in a manner similar to $\mathrm{NAD}^{+} / \mathrm{NADH}$. Because its reduction potential is higher than that of ferredoxin (approximately $-0.39 \mathrm{~V})$, NR could potentially accept electrons from reduced ferredoxin, decreasing $\mathrm{H}_{2}$ production. Although studies on $\mathrm{H}_{2}$ oxidation coupled to ferric iron reduction by Escherichia coli suggested that NR stimulated both 
$\mathrm{H}_{2}$ and formate oxidation (McKinlay and Zeikus 2004), NR addition resulted in accumulation of both $\mathrm{H}_{2}$ and formate in our studies with mixed ruminal microbes. As these two compounds are the primary electron donors in ruminal methanogenesis, it appears that NR's inhibition of methanogenesis may occur via interference with other redox reactions within the methanogenic pathway itself, rather than by inhibiting fermentative production of, or stimulating oxidation of, $\mathrm{H}_{2}$ and formate. It would be of fundamental interest to determine if classical inhibitors of methanogenesis, such as 2-bromoethanesulfonic acid or chlorinated methane analogs, could augment the effects of NR in inhibiting methanogenesis and further extending carbon chain length.

An increased availability of NADH leads to increased production of VFAs, such as valerate and caproate. This is accomplished by reverse $\beta$-oxidation, which sequentially adds acetyl $\left(C_{2}\right)$ units to form butyrate from two molecules of acetate, valerate from acetate and propionate, and caproate from acetate and butyrate (Agler et al. 2012). This is most clearly demonstrated by a sevenfold increase in valerate upon the addition of $1 \mathrm{mM}$ NR (Table 1). Interestingly, the levels of propionate were higher in the NR cultures than in the control, while acetate levels decreased by almost half. Not only did NR increase the concentration of $\mathrm{C}_{5}-\mathrm{C}_{6}$ VFAs, but also $\mathrm{C}_{3}-$ $\mathrm{C}_{4}$ VFAs (propionate and butyrate) as well. So while the average chain length of end-products increased from 2.42 to 2.97 , decreases in end-products only occurred with acetate and methane, the least desirable products in terms of energy content and commercial value.

The levels of total carbon in VFA resulting from MV or NR additions were nearly identical. Of interest is that MV did a significantly poorer job of inhibiting methanogenesis and facilitating chain elongation of acetate. Although Bauchop (1967) demonstrated that the related dye benzyl viologen decreased methanogenesis by mixed ruminal microbes in vitro, the effects on the amounts and distribution of other end products were not reported. The capability of MV to serve as an electron carrier for hydrogenase and increase the availability of NADH for VFA chain elongation was observed by Peguin et al. (1994) who showed MV to increase butyrate concentrations to $0.65 \mathrm{~mol}$ (mol glucose $)^{-1}$ in pure cultures of the nonruminal solventogenic bacterium, Clostridium acetobutylicum. In our experiments, the amount of butyrate was numerically lowered by MV, but the caproate concentration rose to over three times that of the control. This confirms not only that MV is capable of generating butyrate at the expense of shorter products, but also that a second chain elongation to caproate took place despite the short run times, although to relatively modest concentrations.
Of further interest is that NR shifted the fermentation to longer-chain end-products in a concentration-dependent manner. NR was also unaffected by the addition of resazurin as a redox indicator for reducing conditions of the ruminal media. Within the range of concentrations tested, linear decreases in acetate and methane along with increases in $\mathrm{C}_{3}-\mathrm{C}_{6}$ VFA occurred upon additions of greater amounts of NR. This demonstrates that there may be no specific threshold for NR activity. At what NR concentration the linear functions of methane inhibition and VFA chain extension dissipate may depend on the toxicity of the end-products.

At low concentrations, TA had no effect on fermentation product profiles, probably due to its relatively positive redox potential. At the highest concentration tested $\left(1.0 \mathrm{~g} \mathrm{~L}^{-1}\right)$, TA displayed a slight inhibition of switchgrass degradation and a corresponding decrease in methane and propionate formation, and in the ACL of VFA products. In addition, it decreased yield of $\mathrm{C}_{4}-\mathrm{C}_{5}$ branchedchain VFA, which are considered to be produced exclusively by fermentation of branched-chain amino acids (Russell 2002). It is likely that the TA-mediated inhibition of branched-chain VFA production reflects the known ability of tannins to bind proteins and protect them from ruminal degradation (Min et al. 2003).

In this report, we show that certain redox mediators may be an effective means of extending carbon chain length, and we highlight NR as the most effective of the dyes examined. NR is capable of increasing the average carbon chain length of end-products from 2.42 to 2.97 and inhibiting methanogenesis by over half, all while including no additionally added substrates/reagents and keeping fermentation run times at $72 \mathrm{~h}$. The fact that shifts in end product distribution vary dramatically among different redox mediators that differ only slightly in their reduction potential reinforces bioenergetics studies that the ruminal fermentation is primarily under thermodynamic control (Ungerfeld and Kohn 2006). The manipulability of the ruminal system to form higher value fermentation end-products in vitro is clear, and it is a system worthy of further study to identify other, more practical interventions for shifting end product distribution, for potential use on an industrial scale.

\section{Authors' contributions}

PJW conceived the study, MAN and PJW conducted the experiments. MAN and PJW drafted the manuscript. Both authors read and approved the final manuscript.

\section{Author details}

1 'Department of Bacteriology, University of Wisconsin-Madison, Madison, WI 53706, USA. ${ }^{2}$ United States Department of Agriculture, Agricultural Research Service, US Dairy Forage Research Center, 1925 Linden Drive West, Madison, WI 53706, USA. ${ }^{3}$ Present Address: Department of Plant Pathology and Microbiology, Texas A\&M University, 435 Nagle Street, College Station, TX 77843-2132, USA. 


\section{Acknowledgements}

This research was supported by USDA-ARS CRIS projects 3655-4100-006-00D and 3655-21000-022-D. We thank C. L. Odt for HPLC analysis.

\section{Disclaimer}

Products mentioned are for informational purposes only and does not constitute an endorsement or warranty of such products over others that may be similar.

\section{Compliance with ethical guidelines}

\section{Competing interests}

The authors declare that they have no competing interests.

Received: 8 June 2015 Accepted: 17 July 2015

Published online: 04 August 2015

\section{References}

Agler MT, Wrenn BA, Zinder SH, Angenent LT (2011) Waste to bioproduct conversion with undefined mixed cultures: the carboxylate platform. Trends Biotechnol 29:70-78

Agler MT, Spirito CM, Usack JG, Werner JG, Angenent LT (2012) Carbon chain elongation in reactor microbiomes: upgrading dilute ethanol to mediumchain carboxylates. Energy Environ Sci 5:5189-5192

Bauchop T (1967) Inhibition of rumen methanogenesis by methane analogues. J Bacteriol 94:171-175

Goering HK, Van Soest PJ (1970) Forage fiber analysis (apparatus, reagents, procedures and some applications). Agricultural Handbook No. 379, US Department of Agriculture, Washington, DC

Granda CB, Zhu L, Holtzapple MT (2007) Sustainable liquid biofuels and their environmental impact. Environ Prog 26:233-250

Hagerman AE, Riedl KM, Jones GA, Sovik KN, Ritchard NT, Hartzfeld PW et al (1998) High molecular weight plant polyphenolics (tannins) as biological antioxidants. J Agric Food Chem 46:1887-1892

Holtzapple MT, Granda C (2009) Carboxylate platform: the MixAlco process part 1: comparison of three biomass conversion platforms. Appl Biochem Biotechnol 156:525-536

Hongo M (1958) Change of solvent ratio by the addition of neutral red in the fermentation of pentose. Nippon Nogeikagaku Kaischi 32:219-223

Hristov AN, Oh J, Firkins JL, Dijkstra J, Kebreab E, Waghorn G et al (2013) Special topics - mitigation of methane and nitrous oxide emissions from animal operations: I. A review of enteric methane mitigation options. J Anim Sci 91:5045-5069

Hungate RE (1969) Chapter IV: a roll tube method for cultivation of strict anaerobes. Methods Microbiol 3B:117-132

Lange JP, Price R, Ayoub PM, Louis J, Petrus L, Clarke L et al (2010) Valeric biofuels: a platform of cellulosic ethanol fuels. Angew Chem Int Ed 49:4479-4483

Levy PF, Sanderson JE, Kispert RG, Wise DL (1981) Biorefining of biomass to liquid fuels and organic chemicals. Enzyme Microb Technol 3:207-215
McKinlay JB, Zeikus JG (2004) Extracellular iron reduction is mediated in part by neutral red and hydrogenase in Escherichia coli. Appl Environ Microbiol 70:3467-3474

Michaelis L, Hill ES (1933) The viologen indicators. J Gen Physiol 16:859-873

Min BR, Barry TN, Attwood GT, McNabb WC (2003) The effect of condensed tannins on the nutrition and health of ruminants fed fresh temperate forages: a review. Animal Feed Sci Technol 106:3-19

Mouriño FR, Akkarawongsa R, Weimer PJ (2001) pH at the initiation of cellulose digestion determines cellulose digestion rate in vitro. J Dairy Sci 48:848-859

Park DH, Laivenieks M, Guettler MV, Jain MK, Zeikus JG (1999) Microbial utilization of electrically reduced neutral red as the sole electron donor for growth and metabolite production. Appl Environ Microbiol 65:2912-2917

Peguin S, Goma G, Delorme P, Soucaille P (1994) Metabolic flexibility of Clostridium acetobutylicum in response to methyl viologen addition. Appl Microbiol Biotechnol 42:611-616

Rao G, Mutharasan R (1987) Altered electron flow in continuous cultures of Clostridium acetobutylicum induced by methyl viologen dyes. Appl Environ Microbiol 53:1232-1235

Russell JB (2002) Rumen microbiology and its role in ruminant nutrition. James B. Russell, Ithaca

Singhania RR, Patel AK, Christophe G, Fontanille P, Larroche C (2013) Biologica upgrading of volatile fatty acids, key intermediates for the valorization of biowaste through dark anaerobic fermentations. Bioresour Technol 145:166-174

Stieliler RD, Chen TT, Clark WM (1933) Studies on oxidation-reduction. XVIII, Simple safranines. J Am Chem Soc 55:891-907

Ungerfeld EM (2015) Shifts in metabolic hydrogen sinks in the methanogenesis-inhibited ruminal fermentation: a meta-analysis. Front Microbiol 6:37

Ungerfeld EM, Kohn RA (2006) The role of thermodynamics in the control of ruminal fermentation. In: Sejrsen K, Hvelplund T, Nielsen MO (eds) Ruminant physiology: digestion, metabolism and impact of nutrition on gene expression, immunology and stress. Wageningen Academic Publishers, Waginengen, pp 55-85

Weast RC (1969) Handbook of chemistry and physics, 50th edn. Chemical Rubber Company, Cleveland, pp D212-D215

Weimer PJ (2011) End product yields from the extraruminal fermentation of various polysaccharide, protein, and nucleic acid components of biofue feedstocks. Bioresour Technol 102:3254-3259

Weimer PJ, Lopez-Guisa JM, French AD (1990) Effect of cellulose fine structure on kinetics of its digestion by mixed ruminal microorganisms in vitro. Appl Environ Microbiol 56:2421-2429

Weimer PJ, Shi Y, Odt CL (1991) A segmented gas/liquid delivery system for continuous culture of microorganisms on solid substrates, and its use for growth of Ruminococcus flavefaciens on cellulose. Appl Microbiol Biotechnol 36:178-183

Weimer PJ, Russell JB, Muck RE (2009) Lessons from the cow: what the ruminant animal can teach us about consolidated bioprocessing of cellulosic biomass. Bioresour Technol 100:5323-5331

\section{Submit your manuscript to a SpringerOpen ${ }^{\odot}$ journal and benefit from:}

- Convenient online submission

- Rigorous peer review

- Immediate publication on acceptance

- Open access: articles freely available online

- High visibility within the field

- Retaining the copyright to your article

Submit your next manuscript at $\downarrow$ springeropen.com 